ISSN electrónico: 2445-1355

DOI: http://dx.doi.org/10.14201/fj2019428591

\title{
USO DE PROBIÓTICOS EN OFICINA DE FARMACIA DE PONFERRADA (LEÓN) EN EL PERIODO DE FEBRERO A JULIO DEL 2018
}

\section{Use of Probiotics in the Pharmacy Office of Ponferrada (León) from February to July 2018}

Silvia ÁLVAREZ NÚÑEZ; María del Mar ESCUDERO RUBIO

Oficina de farmacia María del Mar Escudero Rubio; Vía Pico Tuerto, 5, 24400, Ponferrada - León. Teléfono 987413603

Correo-e: silvialvarez@usal.es

RESUMEN: Existen diversas patologías o efectos secundarios; como los que puede desencadenar el uso de antibióticos, produciendo numerosos desequilibrios en la microbiota.

Los probióticos son utilizados para tratar o prevenir un amplio espectro de condiciones patológicas o enfermedades.

El consumo de ellos se realiza a través, sobre todo, de las recomendaciones realizadas por médicos y farmaceuticos, cuando los pacientes acuden a ellos, tras cursar diversas patalogías en las que el probiótico puede ayudarles.

Cuando se prescriba el probiótico tanto el farmacéutico como el médico deben comprobar que es el adecuado para la patología que posee el paciente; dependiendo del probiotico poseerá unas cepas concretas que ayudarán a mejorar la patología.

Palabras clave: Probiótico; atención farmacéutica; microbiota.

ABSTRACT: There are various pathologies or side effects, like those that can trigger the use of antibiotics, producing numerous imbalances in the microbiota. 
Probiotics are used to treat or prevent a wide spectrum of pathological conditions or diseases.

The consumption of them is done through above all the recommendations made by doctors and pharmacists, when the patients come to them, after studying various patalogías in which the probiotic can help them.

When the probiotic is prescribed, both the pharmacist and the physician must verify that it is appropriate for the patient's pathology; depending on the probiotic will possess specific strains that will help to improve the pathology.

Key words: Probiotic; Pharmaceutical care; Microbiota.

\section{INTRODUCCIÓN}

Cada vez adquiere mayor importancia la modulación de la flora intestinal mediante el empleo de probióticos, para tratar diversas enfermedades, principalmente problemas gastrointestinales; son también usados con éxito en diversas patologías de la mujer y en la prevención de infecciones.

Existe una Sociedad Española de Probióticos y Prebióticos (SEPyP) que es una organización científica dedicada a la difusión del conocimiento científico de la microbiota de las regiones corporales, probióticos, prebióticos y su impacto en la salud. Su objetivo es promover el conocimiento de las investigaciones realizadas sobre el tema de los probióticos, dando a conocer estudios realizados.

\section{1. ¿Qué son los probióticos?}

Los probióticos son microorganismos (bacterias o levaduras) no patógenos $\mathrm{y}$ viables que son capaces, una vez ingeridos, de alcanzar el intestino y conferir un efecto beneficioso al receptor.

La definición dada por la OMS en el año 2002 es «microorganismos vivos que administrados en cantidades adecuadas promueven beneficios en la salud del huésped».

Estos productos deben haber seleccionado adecuadamente la cepa, realizando ensayos clínicos de calidad para asegurar los beneficios. La acción de un probiótico es específica de cada cepa y para cada patología en concreto en la que se haya demostrado su eficacia con ensayos clínicos.

Las bacterias más utilizadas incluyen especies de Lactobacillus, Bifidobacterium, Escherichia coli, Streptococcus, Enterococcus y Propiniobacterium. 
Poseen un efecto protector que viene determinado por la capacidad de generar compuestos antimicrobianos, entre los que se encuentran fundamentalmente los ácidos láctico, acético, propiónico y/o butírico, que resultan del metabolismo fermentativo de los azúcares, dado que la mayoría de los organismos probióticos son anaerobios aerotolerantes o estrictos. También juega un papel importante la producción de bacteriocinas, que son péptidos que producen poros en la membrana de las bacterias susceptibles o inducen lisis, siendo, por tanto, bactericidas. Por último, la generación de agua oxigenada es algo utilizado en los probióticos vaginales, porque ayuda a la protección de dicha cavidad.

Otra propiedad relevante de algunas cepas probióticas es la de congregar con ciertos patógenos y, en consecuencia, impedir su acceso a las mucosas. La integridad de las mucosas se ve afectada por múltiples factores.

La capacidad de inmunomodulación es una de las actividades que más se ha asociado a los probióticos, produciéndose un amplio espectro de inmunoglobulinas, citocinas, quimiocinas y factores de crecimiento.

Los probióticos son utilizados para tratar o prevenir un amplio espectro de condiciones patológicas o enfermedades.

Las aplicaciones clínicas más relevantes:

- Tratamiento y prevención de diarrea: diferentes microorganismos entre los que se encuentran cepas de Lactobacilos, Bifidobacterias y levaduras, son útiles para el tratamiento y la prevención de la diarrea. Mejoran la reposición de la flora intestinal.

- Alergias: algunos Lactobacilos se han mostrado efectivos en la prevención de dermatitis atópica en niños.

- Síndrome de intestino irritable: este trastorno funcional digestivo que se define clínicamente por la asociación de malestar y dolor abdominal y alteraciones en el número de deposiciones. Los probióticos tienden a disminuir los síntomas como la hinchazón y la flatulencia.

- Tratar síntomas de colitis ulcerosa: previniendo brotes de Pouchitis.

- Terapia coadyuvante para la erradicación del Helicobacter pylori junto con varios antibióticos.

- Estreñimiento funcional.

- Mala absorción de lactosa en adultos: el uso de probióticos se plantea como una alternativa al tratamiento de la mala absorción de la lactosa. Las cepas que presentan mejor resultado son aquellas que presentan actividad lactasa.

- Vulvovaginitis: los diferentes tipos de infecciones del aparato genital femenino comparten diversas manifestaciones como son la presencia de exudado vaginal, picor e irritación vulvar, y en ocasiones olor vaginal. Estos 
procesos se producen cuando hay un sobrecrecimiento de otros tipos de microorganismos más allá de los habituales de la microbiota, produciendo un desequilibrio.

\section{2. Овjetivos}

\subsection{Generales}

- Valorar el uso de probióticos en oficina de farmacia, el conocimiento por parte de los pacientes y el uso.

- Valorar el grado de cumplimiento del tratamiento.

\subsection{Especificos}

- Realizar la atención farmacéutica necesaria y seguimiento farmacoterapéutico con el fin de orientar, asesorar y motivar al paciente para mejorar el estilo de vida, así como el cumplimiento terapéutico.

- Dar información al paciente de los beneficios posibles del uso de los probióticos, con ayuda de folletos de papel.

\section{Materiales y MÉTOdos}

- Se trata de un estudio experimental realizado en una farmacia comunitaria durante 5 meses con pacientes que acuden a la oficina para el consumo de probióticos. La información es recogida a través de la elaboración de encuestas a pacientes.

La encuesta realizada al paciente se divide en tres partes:

Una primera parte, donde se recogen datos del paciente:

- Edad.

- Sexo.

Una segunda, donde se pregunta sobre el grado de conocimiento y el grado de cumplimiento:

- Si los ha consumido o no anteriormente.

- Causa para que los utilizo.

- Si sabe como consumirlos.

- Quién se los recomendó.

Y la tercera parte, donde se llevaría a cabo el seguimiento farmacoterapeutico:

- ¿Para qué los utilizó? 
- ¿Ha seguido el procedimiento?

- Grado de satisfacción del paciente con el tratamiento.

- Forma farmacéutica utilizada.

- ¿Volvería a consumirlos si fuera necesario?

- Realización y distribución de folletos con el fin de proporcionar información a los pacientes sobre los probióticos y el beneficio de sus usos.

- Evaluación de los resultados, analizándolos y estableciendo conclusiones de los resultados obtenidos.

\section{Resultados y discusión}

Fueron encuestados un total de 40 pacientes, de los cuales a 23 se les llevó a cabo un seguimiento terapéutico. El periodo de realización de las encuestas fue de febrero a julio del 2018 en la Oficina de Farmacia María del Mar Escudero Rubio Ponferrada.

\subsection{Datos del paciente}

El mayor porcentaje de consumo se produjo en edades comprendidas entre los 0-8 y entre los 25-65 y el menor uso se produjo en personas mayores de 65 años. El consumo es mayor en mujeres $(60 \%)$ que en hombres (40\%).

\subsection{Grado de conocimiento y cumplimiento}

4.2.1. Seguimiento: hay un porcentaje casi igualitario entre las personas que los han consumido alguna vez con los que no los han consumido nunca. Tan solo un $13 \%$ de los encuestados los consume muy a menudo ( 2 o 3 veces al año).

4.2.2. Utilización: la mayor utilización se produjo para reposición de la flora tras el uso de antibióticos; en la prevención de la diarrea y hongos vaginales producidos tras su uso, sobre todo en tratamientos largos o tras el uso de varias colecciones de antibióticos, como por ejemplo para combatir el Helicobacter pylori.

El uso de antibióticos con mayor resistencia o con principios activos más fuertes, como el clavulánico, también desencadena mayores procesos diarreicos y hongos.

Hemos podido comprobar que los pacientes también los utilizan para procesos diarreicos producidos por causas no derivadas del uso de antibióticos; producidos por virus u otras circunstancias.

Ediciones Universidad de Salamanca / @@ఠ $\quad$ FarmaJournal, vol. 4, núm. 2 (2019), pp. 85-91 
En las mujeres, para el tratamiento de hongos vaginales tiene una gran aceptación; existen cada vez mayor número de probióticos específicos para ese tipo de circunstancias, como son aquellos que llevan en su composición arándano rojo americano, ayudando a restablecer la flora vaginal.

Figura 1. Uso según patología.

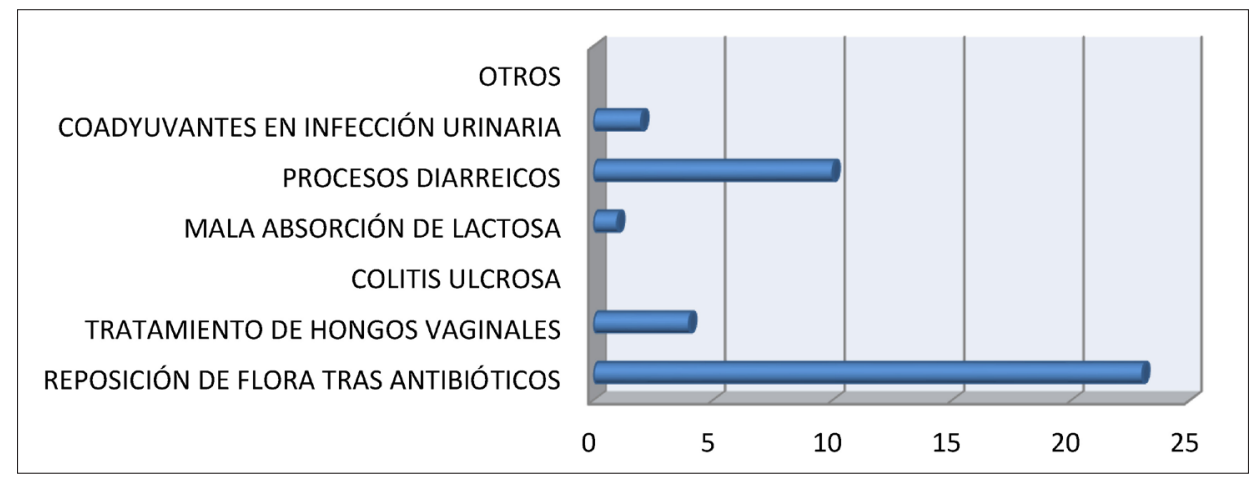

4.2.3. Recomendación: la mayor parte de las veces los pacientes los consumen porque el farmacéutico se los recomiendan, aunque crece el número de veces que el médico los prescribe. Algunas personas también acuden a la oficina de farmacia solicitándolos debido a que han oído o les han comentado que su uso es algo beneficioso, en vías como puede ser internet, personas conocidas que los han consumido y se los recomiendan...

4.2.4. Forma de consumirlos: en el estudio se ha podido ver que la mayor parte de los encuestados sabe cómo consumirlos, aunque afirman que saben hacerlo debido a que el farmacéutico les ha proporcionado diversas explicaciones, dándoles las pautas adecuadas para su correcto uso.

\subsection{Seguimiento farmacoterapentico}

El seguimiento se llevo a cabo en 23 pacientes, de las 40 encuestas realizadas. Después de cumplir con las indicaciones terapéuticas, volvieron a la oficina y nos dieron información de cómo les había ido el proceso.

El $83 \%$ de las personas a las que se les realizo el seguimiento siguió el procedimiento, mientras que un $17 \%$ reconoció no haberlo seguido y entre las causas fue frecuente el olvido. 
Los porcentajes sobre las formas farmacéuticas fueron bastante similares; el frasco monodosis ( $35 \%$ ) debido a su facilidad de uso, fue el más elegido; seguido de cerca por las cápsulas (30\%). Las gotas $(13 \%)$ es el más utilizado para los niños debido a su fácil consumo y que puede camuflarse en agua.

Casi un $80 \%$ de los pacientes encuestados tras la vuelta después de su uso puntuó a los probióticos con una valoración bastante buena (de 8 a 10), un $18 \%$ los puntuó con una valoración buena (de 5 a 7 ) y solo un $4 \%$ de los pacientes encuestados tras el seguimiento los puntuó de 1 a 4 .

El $100 \%$ de los encuestados en el seguimiento volvería a utilizarlos si fuera necesario. Y lo valoran como algo muy positivo.

\section{Conclusiones}

La población que más los consume se sitúa en unas edades comprendidas entre los 25 y los 45 años; aportándoselos también a sus hijos, cuyo porcentaje también es bastante alto.

Son más consumidos por mujeres debido a que tras el uso de antibióticos pueden padecer mayores efectos adversos, siendo más molestos, como pueden ser los hongos vaginales.

Cada vez son mayores las recomendaciones realizadas por médicos y farmacéuticos, tras el estudio de sus múltiples ventajas y el conocimiento de estudios sobre ellos.

\section{Bibliografía}

Álvarez-Calatayud G, Suárez E. Microbiota autóctona, probióticos y prebióticos. Madrid; Pharma\&Helath Consulting. 2014; volumen 28. supl. I.

Guillermo AC, Ascensión MS, Abelardo MB. Probióticos, prebióticos y salud: Evidencia científica. Madrid: Ergon; 2016.

WGO. Probióticos y prebióticos. En: Guias Mundiales de la Organización Mundial de Gastroenterología. 2017. Disponible en: http://www.worldgastroenterology.org/ guidelines/global-guidelines/probiotics-and-prebiotics/probiotics-and-prebioticsspanish

Abelardo MB, Alberto CS, Ana María ML, Ana RS, Ascensión MS, Juan Evaristo SF, Guill AC. Guía de actuación y documento de consenso sobre el manejo de preparados con probióticos y/o prebióticos en la farmacia comunitaria sefac y sepyp. Sociedad Española de Farmacia Comunitaria (sefac); 2018. 